\title{
CARME RIERA: EL SUBJECTE DE LA SEDUCCIÓ
}

\begin{abstract}
Abans de la nova Inquisició, això és, abans que la ignomínia política i la ignorància cultural llancessin un innoble — i per això encara més perillós- atac contra la llengua pròpia, a Mallorca, el 2010, es va celebrar l'any Carme Riera. El resultat de la jornada d'estudi que coronava, simbòlicament, totes les iniciatives illenques fou un volum d'assaigs a cura de Lluïsa Cotoner i Pilar Arnau amb el títol Els subjectes de l'alteritat. Com si es tractés d'un Ianus bifront, aquest llibre fonamenta, juntament amb l'altre monogràfic sobre l'autora que havia publicat la infatigable Cotoner deu anys enrere ( $\mathrm{La}$ identitat $i$ la màscara), les bases teòriques que qualsevol estudiós, estudiosa, interessat a la narrativa de Carme Riera hauria de tenir com a text de capçalera.

D'altra banda, l'existència de dos volums més, sobre la nostra autora, publicats a l'estranger (un en anglès i un altre en castellà) són els indicis d'un èxit acadèmic - i de públic - que ha traspassat els limenes dels Països Catalans. I tanmateix, al mig d'articles, elogis i reconeixements, ens queda encara, des de dins, la sensació d'una absència que dóna un regust amarg i que té a veure més amb la qualitat que amb la quantitat. La referència va cap a la inexistència d'una tesi doctoral defensada dins l'àmbit de la catalanística; en fi, d'algun estudi que sense perdre-hi en rigor i en solidesa- pugui servir d'introducció completa i articulada a la narrativa de l'escriptora mallorquina. L'excepció —un preciós "retrat" fet per Lluïsa Julià i editat per l'Associació d'Escriptors en Llengua Catalana ara fa un llustre- confirma la regla: el pinzell crític traça un dibuix exemplar, però el nombre limitat de pàgines del llibret no permet una anàlisi més sistemàtica i àmplia. No caurem en la falllàcia periodística de repartir culpes per tot arreu: ja sabem que els déus que atribueixen culpes i reparteixen pecats literaris són la part més patètica del nostre univers editorial que genera i nodreix divinitats menors, però considerem que el món universitari de la Filologia Catalana, després d'absorbir el retard cultural d'una dictadura, ara ha d'assumir també el repte d'ocupar-se de la contemporaneïtat més candent, i Carme Riera es presenta, davant els nostres ulls, com un territori fèrtil encara, en part, per explorar.
\end{abstract}


Ara bé, és difícil abraçar tots els aspectes i temes que suggereix la lectura de la seva narrativa. Es palesa de seguida que es tracta d'una autora pròxima al seu temps, avesada a reflectir i elaborar de forma fidel i significativa la representació de la dona, no només com a personatge de ficció diferenciat, sinó, potser més significativament, com a veu marcada, com a eix que vertebra la narració des de la seva personalitat abassegadora, específicament femenina, i des de territoris propis i nous de ficcionalització. És aquí on trobem, precisament, el fil conductor que dóna raó del nostre monogràfic: no debades hem triat el terme "seducció" com a testimoni que s'intercanvien els articles del present dossier.

En el nostre cas, cal esmentar la I Jornada sobre l'obra de creació de Carme Riera. El subjecte de la seducció (novembre de 2010, Centre Dona i Literatura, Universitat de Barcelona), on les aportacions - la major part de les quals composen aquest dossier-, ens van brindar l'ocasió de dialogar, de confegir un espai suggestiu, múltiple i nou, entre les veus que les van presentar i el públic que les va rebre. Editar-ne ara unes versions més elaborades ens ofereix una oportunitat privilegiada per continuar el joc llavors obert: els textos encara inclouen els empelts d'aquella primera trobada, i aquí tenim l'oportunitat de veure com continuen creixent i movent la reflexió i l'escriptura sobre una autora que ha demostrat abastament la fecunditat i l'interès científic que la seva producció desperta. Com si es tractés d'una estructura epistolar, tan rieriana, ara la paraula potser retornarà, curosa i seduïda, a llavis i escrits d'altri.

Carme Gregori ens proposa, en primer lloc, una admirable aportació sobre el caràcter autoficcional de l'obra de Carme Riera. Estudia la ruptura del pacte realista que apareix als textos de manera conscient i recurrent. Es dibuixa, amb plena complicitat, un nou espai, un territori metaficcional, on la creació mostra el seu caràcter fictici i revela els límits i els codis que regeixen les relacions establertes entre literatura i realitat. Es pot pensar que l'aguda troballa de Gregori no ens hauria d'haver sorprès. Ja sabíem que Riera mai no ha practicat una escriptura formalment ingènua i primerenca, no deixa cap petjada conformista de resignació pel fet de ser només trencadorament femenina; la seva mà coneix perfectament les cruilles de la narrativa contemporània, en fa ús i assoleix així una maduresa i una originalitat que situen la metaficcionalitat al bell mig de la problemàtica del subjecte, ben capaç de trencar l'horitzó d'expectatives i arrossegar pels camins incerts del seu laberint narratiu.

Una novel.la concreta és centre d'atenció per a Francesca Bartrina. I heus aquí que molts dels aspectes ja refermats els podríem fer presents pertinentment i complementària, quan ens situem a Cap al cel obert. Són ara, no obstant això, les teories feministes sobre el plaer de la lectura, més aviat, les que n'emmarquen la lectura. Els personatges femenins convoquen les grans teòriques com ara Rubin; un argument secundari permet encabir Diana Fuss i Nancy Miller, mentre que l'epíleg ens insta a donar veu a Susan Lanser i Susan Winnet. Tot ens serveix per donar nou sentit a una història que no acaba en ella mateixa, sinó que, més aviat, 
es prolonga cap a un dona-personatge llegendària, eina renovadora de la memòria colllectiva i parany de seducció, mentre s'esborren, un cop més, les fronteres convencionals entre realitat i ficció.

L'alteritat ens sorprèn gràcies a l'article de Lluïsa Julià. No només hi ressalta la diferència dels xuetes, víctimes de les persecucions del segle XVII, sinó la particularitat, també, que s'hi imagini una escriptora, descendent d'aquests, una veu que reflecteix al si de la ficció les dificultats que s'havien de vèncer i que marca l'origen de la pròpia Riera com a hereva conscient d'aquella primera generació de literates europees, de pioneres en l'art de conquerir l'escriptura. I aquí s'hi afegeixen tècniques d'ironia, de paròdia i de pastitx, perquè l'escriptura esdevingui argument visible, fet rellevant i teixit que mentre ordeix la trama, es fa, ella mateixa, estri deformant i perceptible, mirall de contemplació i reflexió al procés de lectura.

Més endavant, Itàlia ubica l'estudi que ens proposa, lúcidament, Luisa Cotoner. Agent i objecte d'atracció, la península mediterrània forneix escenaris, paisatges, referències i jocs intertextuals a diverses obres rierianes; però, a més a més, la gran recepció de l'escriptora a terres italianes ens permet concloure que Riera ha seduït bona part d'aquell públic. I és, en definitiva, una prova més de la modernitat i pertinència de la seva obra, tan forta com per saltar fronteres des d'una plataforma que, volens nolens, és encara minoritzada, com ara la llengua catalana.

Arribem amb el darrer article a descobrir, de la mà d'Antònia Ramon Villalonga, que algunes pintures suggereixen reflexions sobre la nostra autora a partir de l'antiga màxima horaciana. Dones i paisatge ofereixen, més enllà de citacions explícites i clins d'oeil culturalistes, una mena de mirall mutu, afavorint una correspondència que mai no resulta estàtica - ni tampoc convencional o ornamental-. Així mateix, Villalonga ens mostra com les pintures proporcionen una font d'argument literari i s'insereixen en la narració com a elements estructurals de primer ordre. Fins i tot, en ocasions, prolonguen el fil cap a espais visuals d'evocació i renovació de la pròpia substància narrativa. En fi, una modernitat provocadora, que trena imatges i escriptures de dona.

Seducció, des de la feminitat i la complexitat. Són idees motrius, sempre entrellaçades, amb què formàvem la imatge i l'evocació de la producció de Carme Riera. Així, doncs, la Jornada del 2010 ens va permetre de confirmar abastament aquestes intuïcions. I finalment ha arribat el moment d'agrair a la fotògrafa Ainhoa Valle que hagi acceptat la col-laboració amb una de les seves representacions del cos com a portada que obre el diàleg amb els textos i en fa, tan hàbilment, mirall.

No defugirem confessar que tenim el desig de contribuir, des de la caixa de ressonància que Lectora ens brinda, a refermar i convertir en més i més escoltat el nom de Carme Riera, ja merescudament celebrat al panorama de la cultura catalana contemporània. 
Poques vegades ens sentirem amb més satisfacció, amb més recompensa personal, que després de fer plenament coneguts els fruits d'aquestes tasques d'estudi, inspirades per una obra de llarg recorregut i que es prolongarà, naturalment, molt més enllà d'aquestes pàgines.

MARTA FonT I FRANCESCO ARDOLINO

Universitat de Barcelona 